\title{
Leadership Attitudes and Beliefs of Pharmacy Students: A cross- sectional Study from a Malaysian University
}

\author{
Mohamed Azmi Hassali ${ }^{1}$, Fahad Saleem ${ }^{1}$, Alian A. Alrasheedy ${ }^{2 *}$, Zeehan Shanaz Ibrahim ${ }^{3}$, Tahir Mehmood Khan ${ }^{4}$, \\ Hisham Aljadhey ${ }^{5}$ \\ ${ }^{1}$ Discipline of Social and Administrative Pharmacy, School of Pharmaceutical Sciences, Universiti Sains Malaysia, 11800, Penang, Malaysia. ${ }^{2}$ Pharmacy \\ Practice Department, Unaizah College of Pharmacy, Qassim University, Saudi Arabia. ${ }^{3}$ School of Languages, Literacy and Translation, Universiti Sains \\ Malaysia, 11800, Penang, Malaysia. ${ }^{4}$ Discipline of Pharmacy, Monash University Malaysia, 47500, Bandar Sunway, Selangor, Malaysia. ${ }^{5}$ Department of \\ Clinical Pharmacy, College of Pharmacy, King Saud University, Riyadh, 11451, Saudi Arabia.
}

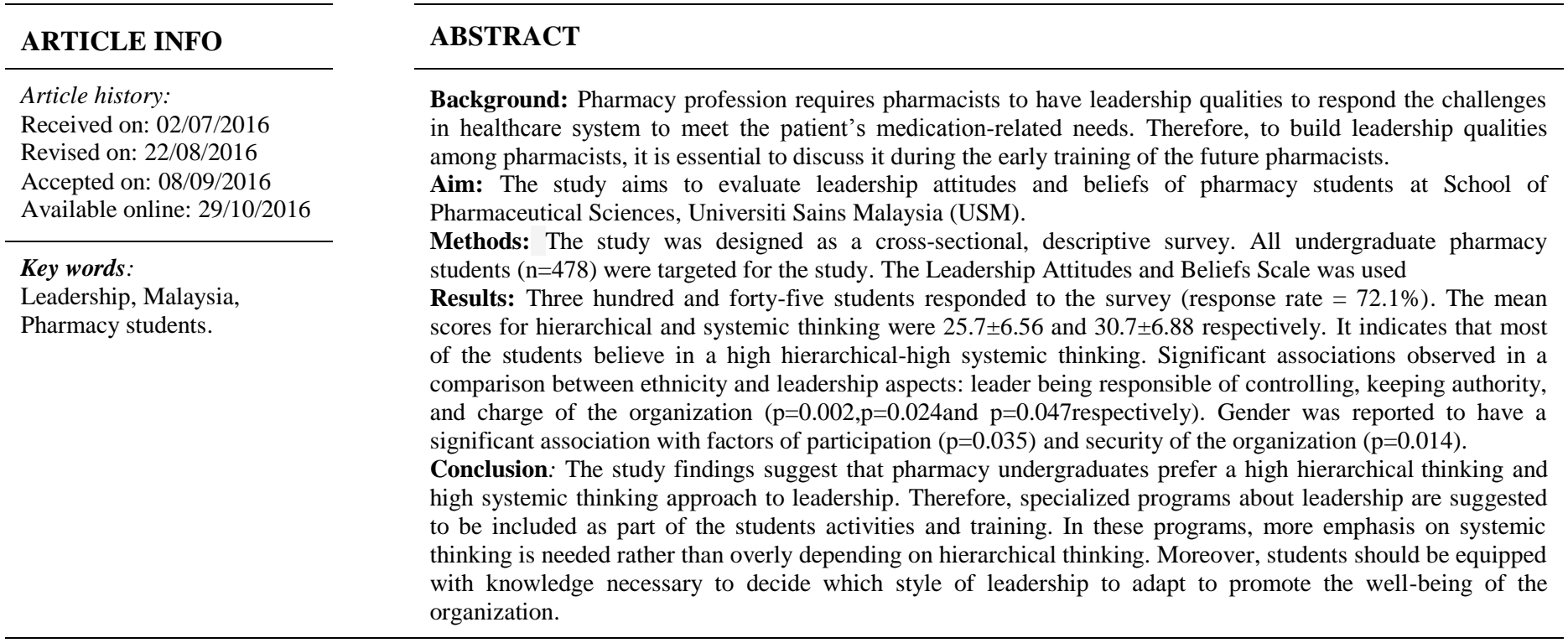

\section{INTRODUCTION}

Pharmacy profession has witnessed a remarkable transformation in the recent decades (Ried and Posey, 2006). One of the key reasons of this transformation was the demand to acquire acquaintance, ability, and principles in developing an ideal pharmaceutical care model for the healthcare system

\footnotetext{
* Corresponding Author

Alian A. Alrasheedy, Pharmacy Practice Department,

Unaizah College of Pharmacy, Qassim University, Saudi Arabia.

Email: alian-a@hotmail.com
}

(Sorensen and Biebighauser, 2003). Within this context, even though pharmacists were actively involved in creating a professional change, pharmacy profession progress in providing patient-oriented services was relatively slower compared to other healthcare professions (Sorensen and Biebighauser, 2003).

The changes in pharmacy profession need not only the leaders (e.g. directors) but every pharmacist to have some leadership qualities to meet the patient's medication-related needs and respond to the challenges in the healthcare system. Therefore, it has been suggested that all pharmacists should have some leadership qualities/traits (White et al., 2003). 
Critics foresee one of the possible solutions to build leadership qualities among pharmacists is by addressing this part during the early training of the future pharmacists (White et al., 2003; Hisholm-Burns et al., 2012).

However, if undergraduate programs are to be looked upon as 'change agents', policy makers have to make sure that leadership is an essential part of the pharmacy curriculum (Sorensen and Biebighauser, 2003). Preparing future leaders in pharmacy requires knowledge, skills, and values inclined towards professional leadership. Therefore, curriculum designers and policy makers must consider whether the current pharmacy-related programs are effectual in preparing pharmacists to take up the role of change agents in future (Kotter 1996; Astin and Astin, 2000).

In addition, for the survival, performance and sustainability of the pharmacy profession, strong and effective leadership skills are also required. Therefore, it is crucial that institutions offering pharmacy education give many practical opportunities for students to develop leadership skills.

The leadership has been discussed in literature with several studies and perspectives are published (Wielkiewicz, 2000; Fischer et al., 2010; Lowhorn, 2011; Feller et al., 2016; Saleem et al., 2016; Waddell et al., 2016). Fischer et al (2010) stated that, according to ecological model of leadership, "effective leadership involves atension between hierarchical and systemic approaches to leadership". In the hierarchal model of leadership, the leader is perceived to have a special or better knowledge than the group members. Moreover, the leader assumes full responsibility for the organization. Furthermore, in this model, the involvement of subordinates in the decision-making process and provision of their feedback is limited. As such, the group members are task-oriented with top-down flow of directives are given by the leader of the organization (Wielkiewicz, 2000; Fischer et al., 2010; Lowhorn, 2011).

On the contrary, systemic leadership provides the group/organization members with the freedom and feedback loops necessary for the involvement in the decision-making process and to facilitate the organization's ability to adapt to changes (Fischer et al., 2010; Lowhorn, 2011). Therefore, Fischer et al (2010) stated in their conclusion that effective leaders are required to have the attitudes and beliefs necessary to act as both a systemic leader and a hierarchical leader.

The leader must also have knowledge necessary to decide which style of leadership to adapt to promote the well-being of the organization". As development of leadership skills among students is currently an area of major interest for Pharmacy programs (Feller et al., 2016), the aim of this study is, therefore, to find the leadership attitudes and beliefs of pharmacy undergraduates enrolled at School of Pharmaceutical Sciences, USM. By assessing the results of the current leadership survey, the study can serve as a needs assessment for leadership training programs at pharmacy schools in the country, as it seems that yet no studies conducted on pharmacy undergraduates' leadership style in Malaysia.

\section{METHODS}

\section{Study Design, Settings, and Sampling Frame}

The study was designed as a questionnaire-based, crosssectional survey. All pharmacy undergraduates $(n=478)$ enrolled at the School of Pharmaceutical Sciences, USM were targeted for the study and invited for participation.

\section{Study instrument}

The Leadership Attitudes and Beliefs Scale (LABS-III) was used to identify the leadership attitudes and beliefs (Wielkiewicz, 2000). The leadership model suggests that people can be categorized into one of four preferred styles of leadership, namely High hierarchical-High systemic (HH-HS), High hierarchical-Low systemic (HH-LS), Low hierarchical-High systemic (LH-HS) and Low hierarchical-Low systemic (LH-LS).

LABS-III is a 28-itemed, 5-point Likert-type instrument with responses ranging from strongly agree to strongly disagree. Of these items, 14 are hierarchical thinking while the other 14 related to systemic thinking (Wielkiewicz, 2000). Lower scores in hierarchical and systemic thinking are associated with stronger beliefs in each area (Scores range from 14 to 70). According to Wielkiewicz (2000), the hierarchical thinking suggests that the power and control are focused in the upper levels of the hierarchy and characterized by the belief that the authority extends downwards the hierarchy and members should seek guidance form the higher levels while the systemic thinking is characterized by the ability to relate the success of the organization to the complex interaction of several factors including the cooperation of all members (Wielkiewicz, 2000).

Prior to use the LABS-III permission was obtained from the developers. A panel of experts at School of Pharmaceutical Sciences conducted the validity analysis. The tool was piloted with 25 students to ensure the validity and reliability of the questionnaire in the Malaysian setting. With the recommendation of minor changes, alpha coefficient suggested a high level of internal consistency $(\alpha=0.871$ and 0.783 for systemic and hierarchical scales respectively) with an alpha value of 0.801 for all 28 items collectively.

\section{Statistical analysis}

The data were entered and analysed using the Statistical Package for Social Sciences (SPSS version 18.0, SPSS Inc., Chicago, IL, USA).

The results of each item on the questionnaire were reported, as frequencies and percentages. The Kolmogrov-Smirnov test was used for normality assessment. The Chi-squared test was used to observe the significance of observed distribution. When significant associations were reported, effect size was calculated by using Phi or Cramer's V constant wherever appropriate. The relationship between hierarchical thinking scale and systemic thinking scale was tested by using Spearman's rank correlation coefficient. $\mathrm{P}$ value of $<0.05$ was considered to be of a statistical significance. 


\section{Ethical approval}

The Institutional Review Board of Discipline of Social and Administrative Pharmacy, School of Pharmaceutical Sciences, USM approved the study. Written and signed consent was also obtained from the respondents prior to data collection.

\section{RESULTS}

\section{Demographics and characteristics of the study respondents}

Three hundred and forty five students responded to the survey, giving a response rate of $72.1 \%$. Majority of the respondents were female students $(n=279,80.9 \%)$ with mean age of 20.4 years.

The majority $(n=294,85.2 \%)$ had matriculation level of education before joining the pharmacy program. More than half of the respondents $(n=184,53.3 \%)$ reported themselves as Malay ethnic group (Table 1).

Table 1: Demographic characteristics of the study respondents.

\begin{tabular}{|c|c|c|}
\hline Characteristics & Frequency & Percentage \\
\hline \multicolumn{3}{|l|}{ Age $(20.4 \pm 1.19)$} \\
\hline 18 & 1 & 0.3 \\
\hline 19 & 88 & 25.5 \\
\hline 20 & 98 & 28.4 \\
\hline 21 & 72 & 20.9 \\
\hline 22 & 76 & 22.0 \\
\hline 23 & 8 & 2.3 \\
\hline 24 & 2 & 0.6 \\
\hline \multicolumn{3}{|l|}{ Gender } \\
\hline Male & 66 & 19.1 \\
\hline Female & 279 & 80.9 \\
\hline \multicolumn{3}{|l|}{ Ethnicity } \\
\hline Malay & 184 & 53.3 \\
\hline Chinese & 127 & 36.8 \\
\hline Indians & 23 & 6.7 \\
\hline Others & 11 & 3.2 \\
\hline \multicolumn{3}{|l|}{ Year of study } \\
\hline First year & 100 & 29.0 \\
\hline Second year & 90 & 26.1 \\
\hline Third year & 69 & 20.0 \\
\hline Fourth year & 86 & 24.9 \\
\hline \multicolumn{3}{|l|}{ Mode of entry } \\
\hline STPM & 20 & 5.8 \\
\hline A-Levels & 7 & 2.0 \\
\hline Matriculation & 294 & 85.2 \\
\hline Diploma & 3 & 0.9 \\
\hline Others & 21 & 6.1 \\
\hline
\end{tabular}

\section{Leadership attitudes and beliefs of pharmacy undergraduates}

Table 2 depicts the responses of pharmacy students towards LABS-III. Although the study participants were positive in their approach towards innovation, flexibility, adaptability and ethical issues of leadership, intrusive characteristics were still prevalent.

Within this context, $71 \%$ of the respondents agreed that the leadership should control, maintain authority, and take complete charge of the organization. Leadership was perceived as a characteristic of a single person in the organization; hence, $58 \%$ of the respondents were in favour of one group-one leader phenomenon. Furthermore, $43 \%$ of the respondents rated leaders as most important members of the organization and therefore expected that the leaders must carry out all decision and communications because of their risk taking responsibility.

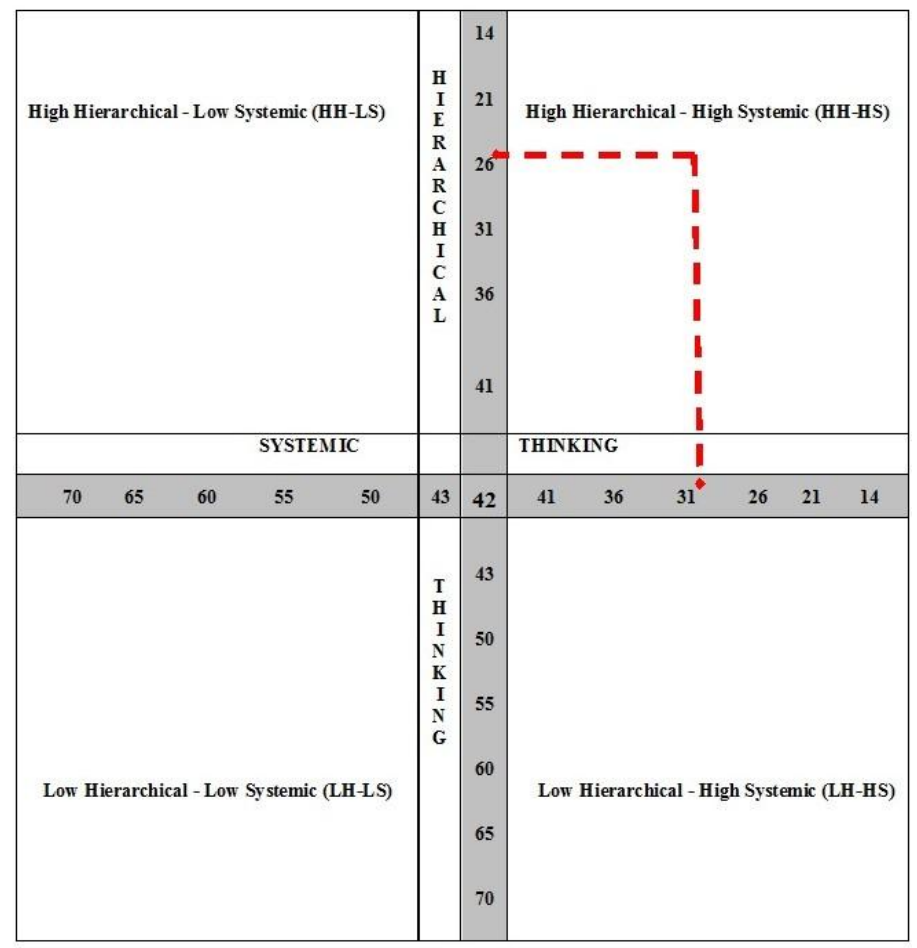

Fig. 1: Leadership attitudes and beliefs of pharmacy undergraduates. Y-axis: hierarchal thinking, (scores ranging from top to bottom $=$ lower to higher scores). X-axis: systemic thinking, (scores ranging from right to left $=$ lower to higher scores). Note: Lower scores in hierarchical and systemic thinking are associated with stronger beliefs in each area (Scores range from 14 to 70).

The reported leadership attitudes and beliefs among respondents are presented in Figure 1. The mean scores (standard deviation) for reported hierarchical and systemic thinking were 25.7 (6.56) and 30.7 (6.88) respectively. Based on the study results, the majority of the respondents were reported to have a High hierarchical-High systemic thinking attitudes and beliefs regarding leaderships. Therefore, the study respondents believed leaders are overly dependent upon hierarchy thinking.

\section{Comparison of study statements and demographic characteristics}

Table 3 describes the cross-tabulation analysis of the study statements and demographic characteristics. Significant associations were observed when in a comparison between ethnicity and leadership aspects: leader being responsible of controlling, keeping authority, and charge of the organization ( $p=0.002,0.024$, and 0.047 respectively). The Cramer's V constant reported a positive and moderate association among the three leadership characteristics $(\varphi c=0.421$ for control, $\varphi c=0.399$ for 
Table 2: Pharmacy students' responses to Leadership Attitudes and Beliefs Scale.

\begin{tabular}{|c|c|c|c|c|c|}
\hline Items & $\begin{array}{c}\text { SA* }^{*} \\
\mathbf{N}(\%)\end{array}$ & $\begin{array}{c}\mathbf{A}^{*} \\
\mathbf{N}(\%)\end{array}$ & $\begin{array}{c}\mathbf{N}^{*} \\
\mathbf{N}(\%)\end{array}$ & $\begin{array}{c}\mathbf{D}^{*} \\
\mathbf{N}(\%)\end{array}$ & $\begin{array}{c}\text { SD* } \\
\mathbf{N}(\%)\end{array}$ \\
\hline \multicolumn{6}{|l|}{ Hierarchical thinking sacle } \\
\hline 1. A leader must control the group or organization. & $81(23.5)$ & $166(48.1)$ & $62(18.0)$ & $30(8.7)$ & $6(1.7)$ \\
\hline 2. A leader must maintain tight control of the organization. & $84(24.3)$ & $138(40.0)$ & $76(22.0)$ & $44(12.8)$ & $3(0.9)$ \\
\hline 3. A leader should maintain complete authority. & $13(3.8)$ & $120(34.8)$ & $99(28.7)$ & 64 (18.6) & $19(5.5)$ \\
\hline 4. A leader should take charge of the group. & $90(26.1)$ & $184(53.3)$ & $56(16.2)$ & $14(4.1)$ & $1(0.3)$ \\
\hline 5. The main tasks of a leader are to make and then communicate decisions. & $105(30.4)$ & $183(53.0)$ & $34(9.9)$ & $20(5.8)$ & $3(0.9)$ \\
\hline 6. The main task of a leader is to make the important decisions for an organization. & $113(32.8)$ & $149(43.2)$ & $56(16.2)$ & $21(6.1)$ & $6(1.7)$ \\
\hline 7. Positional leaders deserve credit for the success of an organization & $61(17.7)$ & $145(42.0)$ & $101(29.3)$ & $30(8.7)$ & $8(2.3)$ \\
\hline 8. The responsibility for taking risks lies with the leaders of an organization. & 47 (13.6) & $152(44.1)$ & $95(27.5)$ & 47 (13.6) & $4(1.2)$ \\
\hline 9. It is important that a single leader emerge in a group. & 85 (24.6) & $119(34.5)$ & $100(29.0)$ & $33(9.6)$ & $8(2.3)$ \\
\hline 10. Members should be completely loyal to the designated leaders of an organization. & $87(25.2)$ & $164(47.5)$ & $69(20.0)$ & $23(6.7)$ & $2(0.6)$ \\
\hline 11. The most important members of an organization are its leaders. & $57(16.5)$ & $92(26.7)$ & $94(27.2)$ & $74(21.4)$ & $28(8.1)$ \\
\hline 12. When an organization is in danger of failure, new leaders are needed to fix its problems. & 40 (11.6) & $77(22.3)$ & $118(34.2)$ & $86(24.9)$ & $24(7.0)$ \\
\hline 13. Leaders are responsible for the security of organization members. & $86(24.9)$ & $163(47.2)$ & $71(20.6)$ & $22(6.4)$ & $3(0.9)$ \\
\hline 14. An organization should try to remain as stable as possible. & $169(49.0)$ & $136(39.4)$ & $31(9.0)$ & $7(2.0)$ & $2(0.6)$ \\
\hline \multicolumn{6}{|l|}{ Systemic thinking scale } \\
\hline 15. An effective organization develops its human resources. & $119(34.5)$ & $173(50.1)$ & $45(13.0)$ & $4(1.2)$ & $4(1.2)$ \\
\hline 16. Leadership activities should foster discussions about the future. & 99 (28.7) & $190(55.1)$ & $51(14.8)$ & $3(0.9)$ & $2(0.6)$ \\
\hline 17. Effective leadership seeks out resources needed to adapt to a changing world. & $114(33.0)$ & $178(51.6)$ & $45(13.0)$ & $6(1.7)$ & $2(0.6)$ \\
\hline 18. Individuals need to take initiative to help their organization accomplish its goals. & $210(60.9)$ & $124(35.9)$ & $7(2.0)$ & $2(0.6)$ & $2(0.6)$ \\
\hline 19. Leadership should encourage innovation. & $145(42.0)$ & $173(50.1)$ & $21(6.1)$ & $4(1.2)$ & $2(0.6)$ \\
\hline 20. Organizational actions should improve life for future generations. & $124(35.9)$ & $176(51.0)$ & $41(11.9)$ & $2(0.6)$ & $2(0.6)$ \\
\hline $\begin{array}{l}\text { 21. Everyone in an organization needs to be responsible for accomplishing organizational } \\
\text { goals. }\end{array}$ & $238(69.0)$ & $96(27.8)$ & $7(2.0)$ & $2(0.6)$ & $2(0.6)$ \\
\hline 22. Leadership processes involve the participation of all organization members. & $182(52.8)$ & $132(38.3)$ & $24(7.0)$ & $6(1.7)$ & $1(0.3)$ \\
\hline 23. Anticipating the future is one of the most important roles of leadership processes. & $70(20.3)$ & $194(56.2)$ & $64(18.6)$ & $11(3.2)$ & $6(1.7)$ \\
\hline 24. Good leadership requires that ethical issues have high priority. & $106(30.7)$ & $170(49.3)$ & $58(16.8)$ & $10(2.9)$ & $1(0.3)$ \\
\hline 25. Successful organizations make continuous learning their highest priority. & $133(38.6)$ & $176(51.0)$ & $30(8.7)$ & $5(1.4)$ & $1(0.3)$ \\
\hline 26. Environmental preservation should be a core value of every organization. & $76(22.0)$ & $161(46.7)$ & $94(27.2)$ & $12(3.5)$ & $2(0.6)$ \\
\hline 27. Organizations must be ready to adapt to changes that occur outside the organization. & $140(40.6)$ & $171(49.6)$ & $27(7.8)$ & $6(1.7)$ & $1(0.3)$ \\
\hline 28. An organization needs flexibility in order to adapt to a rapidly changing world. & $152(44.1)$ & $154(44.6)$ & $32(9.3)$ & $5(1.4)$ & $2(0.6)$ \\
\hline
\end{tabular}

*SA=strongly agree, $\mathrm{A}$-agree, $\mathrm{N}=$ neutral, $\mathrm{D}=$ disagree, $\mathrm{SD}=$ strongly disagre.

Table 3: Cross tabulation of study statements and demographic characteristics.

\begin{tabular}{|c|c|c|c|c|c|}
\hline \multirow[t]{2}{*}{ Items } & \multicolumn{5}{|c|}{ P-value* } \\
\hline & Age & Gender & Ethnicity & Year of study & Mode of entry \\
\hline Individuals need to take initiative to help their organization accomplish its goals. & 0.235 & 0.254 & 0.411 & 0.158 & 0.048 \\
\hline Leadership should encourage innovation. & 0.485 & 0.322 & 0.745 & 0.150 & 0.155 \\
\hline A leader must maintain tight control of the organization. & 0.366 & 0.248 & 0.002 & 0.441 & 0.988 \\
\hline Everyone in an organization needs to be responsible for accomplishing organizational goals. & 0.352 & 0.089 & 0.351 & 0.532 & 0.424 \\
\hline Leadership processes involve the participation of all organization members. & 0.249 & 0.035 & 0.159 & 0.568 & 0.527 \\
\hline A leader must control the group or organization. & 0.458 & 0.231 & 0.477 & 0.579 & 0.125 \\
\hline A leader should maintain complete authority. & 0.844 & 0.556 & 0.024 & 0.325 & 0.258 \\
\hline A leader should take charge of the group. & 0.121 & 0.217 & 0.047 & 0.779 & 0.433 \\
\hline Organizational actions should improve life for future generations. & 0.565 & 0.289 & 0.255 & 0.111 & 0.588 \\
\hline The main task of a leader is to make the important decisions for an organization. & 0.988 & 0.326 & 0.187 & 0.144 & 0.214 \\
\hline Leadership activities should foster discussions about the future. & 0.247 & 0.147 & 0.656 & 0.265 & 0.068 \\
\hline Effective leadership seeks out resources needed to adapt to a changing world. & 0.744 & 0.547 & 0.877 & 0.331 & 0.512 \\
\hline The main tasks of a leader are to make and then communicate decisions. & 0.655 & 0.365 & 0.851 & 0.745 & 0.296 \\
\hline An effective organization develops its human resources. & 0.712 & 0.441 & 0.265 & 0.426 & 0.393 \\
\hline It is important that a single leader emerge in a group. & 0.258 & 0.215 & 0.324 & 0.358 & 0.144 \\
\hline Members should be completely loyal to the designated leaders of an organization. & 0.248 & 0.325 & 0.145 & 0.178 & 0.117 \\
\hline The most important members of an organization are its leaders. & 0.362 & 0.278 & 0.278 & 0.153 & 0.084 \\
\hline Anticipating the future is one of the most important roles of leadership processes. & 0.148 & 0.144 & 0.168 & 0.745 & 0.813 \\
\hline Good leadership requires that ethical issues have high priority. & 0.455 & 0.745 & 0.255 & 0.752 & 0.557 \\
\hline Successful organizations make continuous learning their highest priority. & 0.587 & 0.368 & 0.326 & 0.369 & 0.974 \\
\hline Positional leaders deserve credit for the success of an organization & 0.159 & 0.091 & 0.419 & 0.351 & 0.264 \\
\hline The responsibility for taking risks lies with the leaders of an organization. & 0.247 & 0.478 & 0.078 & 0.668 & 0.741 \\
\hline Environmental preservation should be a core value of every organization. & 0.598 & 0.144 & 0.095 & 0.952 & 0.451 \\
\hline Organizations must be ready to adapt to changes that occur outside the organization. & 0.500 & 0.547 & 0.287 & 0.699 & 0.588 \\
\hline When an organization is in danger of failure, new leaders are needed to fix its problems. & 0.247 & 0.232 & 0.533 & 0.248 & 0.569 \\
\hline An organization needs flexibility in order to adapt to a rapidly changing world. & 0.820 & 0.658 & 0.544 & 0.182 & 0.621 \\
\hline Leaders are responsible for the security of organization members. & 0.357 & 0.014 & 0.325 & 0.009 & 0.099 \\
\hline An organization should try to remain as stable as possible. & 0.657 & 0.287 & 0.001 & 0.441 & 0.074 \\
\hline
\end{tabular}


authority and $\varphi c=0.417$ for charge of the organization). In addition, significant association was also reported when ethnic group were compared with, 'leaders are responsible for the security of organization members $(\mathrm{p}=0.001)$ ' with moderate and positive correlation $(\varphi c=0.254)$.

Gender was also reported to have a significant association with factors of participation and security of the organization. Majority of female participants suggested that leadership processes involve the participation of all organization members $(p=0.035, \varphi c=0.521)$. Furthermore, female participants reported higher agreement that leaders are responsible for the security of organization members $(p=0.014, \varphi c=0.100)$. In this study, however, no significant associations were found between the other items and rest of the study variables.

Spearman's rank correlation coefficient was used to illustrate the nature and level of association among hierarchical and systemic thinking scales. There was a statistically significant positive and moderate relationship between hierarchical and systemic thinking scales $(r=0.478, p<0.01)$.

\section{DISCUSSION}

The study aimed to evaluate the leadership attitudes and beliefs of pharmacy undergraduates. Based on the results, the tendency of pharmacy undergraduates to use systemic thinking in leadership process was directly related to that of hierarchical thinking. Furthermore, the level of hierarchical thinking of pharmacy undergraduates in our study was higher when compared with other similar studies (Wielkiewicz, 2000; Fischer et al., 2010). In addition to the difference of study subjects, a possible reason of this difference in leadership style could be attributed to the traditional views in some parts of Asia that typically use hierarchical thinking in leadership and place less emphasis on systemic thinking (Xin and Tsui, 1996). Within this context, people with hierarchical thinking in leadership, favour chain of command, oversee their subordinates, and support low-quality exchange relationships. Our proposition revolves around the leader-member exchange (LMX) theory that states that leaders with systemic thinking offer independence and responsibility to the employees, hence upholding high-quality relationships (Brower et al., 2000; Sahin 2012). In the light of this discussion, it is necessary to design leadership training modules for pharmacy undergraduates to develop the attitudes and beliefs necessary to act as both a systemic and a hierarchical leader. The students' leadership attitudes and beliefs were associated with their ethnicity. Statistically, significant associations reported whereby the respondents agreed that a leader should maintain control, authority, and charge of the organization. In terms of organization permanence majority of the respondents, belonging to the Chinese and Indian ethnic groups strongly agreed that the organization should stay stable. It is reported that ethnic minority leaders might feel their ethnicity pose a barrier or challenge to accessing leadership roles (Chin, 2013), therefore, they have a higher agreement that it is important for the organization to remain stable as compared to the ethnic of the majority. The differences in the leadership styles among the ethnic groups in the present study could be related to the cultural and religious backgrounds in Malaysia as each ethnic group is influenced by different philosophies in their respective leadership styles (Selvarajah and Meyer 2008).In a country with a variety of subcultures resulting from the different races, the understanding of these cultural values is, therefore, important. Consequently, leadership-based activities must be designed according to these cultural values to make sure that the results from these activities can make the greatest impact on students' perception and attitude towards professional leadership (Chong and Thomas, 1997).

In addition to the ethnic groups, there was a significant association between respondents' gender and their opinion on leadership processes that involve the participation of all organization members with women having higher level of agreement with the statement. Therefore, the present study shows that women favour the participation of all organization members to carry out a given task. This is perhaps could be because women embrace more interpersonal leadership styles, since men are are more task-oriented in their approach (Eagly and Karau, 1991). Moreover, a significant association was reported between gender and security of organization members. Females were more in support that leaders should play their role to secure all organization members. Within this context, security is reported as a priority issue while working in any kind of organization (Oldham et al., 1986) and women were reported to work openly in organizations that offergood security to them. In addition, females perceived that it is the job of the organization leaders to play their roles in providing security (Quesenberry and Trauth, 2007). This finding is confirmed by the present study.

\section{CONCLUSION}

The study findings suggest that pharmacy undergraduates at the School of Pharmaceutical Sciences, USM prefer a high hierarchical thinking and a high systemic thinking approach in leadership. Moreover, the student's leadership style preference was influenced by their gender and ethnic group. Therefore, in order to develop effectual leadership skills among students, leadership development programs that consider the gender and ethnic group should be introduced at the school level. Such programs should be offered to fresh undergraduates more often to change their perceptions and hence produce the desired impact by developing leadership skills among students. Special attention should be given to developing leaders who recognize and value the importance of both hierarchical and systemic forms of leadership. This blend of hierarchical and systemic skills will help students understand and value the important role that leadership plays in facilitating the adaptation and long-term survival of the organization, at the same time, not devaluing the importance of embracing the role of hierarchical or systemic leadership when deemed necessary for the organization. 


\section{LIMITATIONS}

The study was conducted in only one School of Pharmacy in Malaysia. Hence, the findings might not be possible to be generalized to the pharmacy schools in the country. Furthermore, the findings represented the students' perspectives only. Hence, other stakeholders' perspectives need to be explored to have a full picture about this aspect.

\section{Financial support and sponsorship: Nil.}

Conflict of Interests: There are no conflicts of interest.

\section{REFERENCES}

Astin AW, Astin HS. 2000. Leadership Reconsidered: Engaging Higher Education in Social Change. Battle Creek, Mich: W.K. Kellogg Foundation.

Brower HH, Schoorman FD, Tan HH. A model of relational leadership: The integration of trust and leader-member exchange. Leadersh Q, 2000;11, 227-250.

Chin JL. Diversity Leadership: Influence of Ethnicity, Gender, and Minority Status. Open Journal of Leadership, 2013;2:1-10.

Chisholm-Burns MA, Vaillancourt AM, Shepherd M. 2012. Pharmacy management, leadership, marketing, and finance. Jones \& Bartlett Publishers.

Chong LMA, Thomas DC. Leadership perceptions in crosscultural context: Pakeha and Pacific islanders in New Zealand. Leadersh Q,1997; 8, 275-293.

Eagly AH, \& Karau, S. J. Gender and the emergence of leaders: A meta-analysis. Journal of Personality and Social Psychology, 1991; 60, $685-710$

Feller, TT, Doucette WR, \& Witry MJ. Assessing Opportunities for Student Pharmacist Leadership Development at Schools of Pharmacy in the United States. Am J Pharm Educ,2016;80:article no. 79

Fischer DV, Overland M, Adams L. Leadership attitudes and beliefs of incoming first-year college students. J Leadersh Edu, 2010; 9, $1-16$.

Kotter JP. 1996. Leading Change. Boston, Mass: Harvard Business School Press.
Lowhorn, G.L., A Confirmatory Factor Analysis of the Leadership Attitudes and Beliefs Scale-III.IntJ Arts Sci. 2011; 4: 284-296.

Ried LD, Posey LM.The changing face of pharmacy. J Am Pharm Assoc, 2006; 46, 320-321.

Oldham GR, Kulik CT, Stepina LP, Ambrose ML. Relations between situational factors and the comparative referents used by employees. Acad Manage J., 1986; 29(3), 599-608.

Quesenberry JL, Trauth EM. 2007. What do women want?: an investigation of career anchors among women in the IT workforce. ACM Digital Library 122-127

Sahin F. The mediating effect of leader-member exchange on the relationship between Theory $\mathrm{X}$ and $\mathrm{Y}$ management styles and affective commitment: A multilevel analysis. J Manag Organ, 2012; 18, 159-174.

Saleem F, Hassali MA and AljadheyH, Incorporating the concept of leadership in pharmacy curriculums of developing nations. Res Social Adm Pharm, 2016; 12: 668

Selvarajah C, Meyer D. One nation, three cultures: exploring dimensions that relate to leadership in Malaysia. Leadersh Organ Develop J, 2008; 29, 693-712.

Sorensen TD, Biebighauser SM. Pharmaceutical care leadership: an innovative pharmacy practice residency model. J Am Pharm Assoc, 2003; 43:527-532.

Xin KR, Tsui AS. Different strokes for different folks? Influence tactics by Asian-American and Caucasian-American managers. Leadersh Q, 1996; 7: 109-132

Waddell JJ, Hale AR and Nissen LM, Advanced pharmacy practice and leadership. Res Social Adm Pharm,2016; 12: p.662.

White SJ, Wilkin NE, McElroy SR. Leadership development: Empowering others to take an active role in patient care. J Am Pharm Assoc, 2003; 52, 308-318.

Wielkiewicz RM. The Leadership Attitudes and Beliefs Scale: An instrument for evaluating college students' thinking about leadership and organizations. J Coll Stud Dev, 2000; 41:335-347.

\section{How to cite this article:}

Hassali MA, Saleem F, Alrasheedy AA, Ibrahim ZS, Khan TM, Hisham Aljadhey. Leadership Attitudes and Beliefs of Pharmacy Students: A cross-sectional Study from a Malaysian University. J App Pharm Sci, 2016; 6 (10): 189-194. 